A review of prospective memory impairments in developmental dyslexia: Evidence, explanations, and future directions

James H. Smith-Spark ${ }^{\mathrm{a}}$ *

${ }^{a}$ School of Applied Sciences, London South Bank University, London, United Kingdom

*Division of Psychology, School of Applied Sciences, London South Bank University, 103 Borough Road, London, SE1 0AA, United Kingdom. Tel. +44 (0)20 78155884. Emailsmithspj@lsbu.ac.uk 


\section{A review of prospective memory impairments in developmental dyslexia: Evidence, explanations, and future directions}

Objective: The effects of developmental dyslexia are not restricted solely to the processes involved in reading and spelling. Despite this broader impact on cognition, there has been very little dyslexia-related research on prospective memory (PM; memory for delayed intentions) until very recently. This paper focuses on reviewing a recent program of research which sought to explore this memory system in adults with dyslexia. Method: The review focuses mainly on studies of adults with dyslexia in which PM was compared with that of IQmatched adults without dyslexia across clinical measures, computerized tests, self-report questionnaire, and more naturalistic tasks. Results: Across the reviewed studies, the adults with dyslexia showed a range of impairments in both laboratory and everyday settings. Dyslexia-related PM impairments occurred predominantly when cues to remembering were time-based rather than being cued by events in the environment, when delays to act upon the intention were prolonged, and when tasks were one-off events rather than being habitual. As well as being less accurate in their PM, the participants with dyslexia were also less likely to remember PM instructions over longer delay periods. Conclusions: PM deficits in dyslexia are considered in terms of the retrospective and prospective components of PM function. Less efficient access to verbal information in long-term memory, problems with time perception, and poorer executive functions are all considered as potential explanations for less accurate PM in dyslexia. The findings from the research program are linked to broader dyslexia theory and research. Some potential means for supporting individuals with dyslexia are considered.

Keywords: developmental dyslexia; prospective memory; retrospective memory; executive functioning; time perception

\section{Developmental dyslexia}

Developmental dyslexia (henceforth, dyslexia) is characterized by core deficits in phonological processing (for reviews, see Castles \& Friedmann, 2014; Vellutino, Fletcher, Snowling \& Scanlon, 2004). Alongside its well-documented effects on the processes involved in reading and spelling, dyslexia has also been found to be 
associated with broader impairments in cognition (e.g., Booth, Boyle \& Kelly, 2010; Bogaerts et al., 2015; Menghini, Finzi, Carlesimo \& Vicari, 2011; Smith-Spark, Fisk, Fawcett \& Nicolson, 2003; Smith-Spark, Henry, Messer, Edvardsdottir \& Zięcik, 2016). Given the potentially wide-ranging consequences of such problems, it is important to gain a more detailed understanding of how the impact of dyslexia may extend beyond tasks involving literacy skills. To this end, the current paper reviews research on prospective memory (PM), an area of cognition which has been more-or-less ignored in the developmental dyslexia literature until very recently, despite this memory system being called upon on a daily basis across a range of different situations (e.g., McDaniel \& Einstein, 2007). A better understanding of the impact of dyslexia on PM can then be used to support individuals with dyslexia across personal, educational, and employment settings.

\section{Prospective memory}

Prospective memory is memory for delayed intentions (Winograd, 1988) or “remembering to remember” (Mäntylä, 1994). All PM tasks share two common components. A prospective (or planning) component serves to remind the individual at the appropriate moment that an intention needs to be acted upon, whilst a retrospective component is responsible for providing the individual with the detail of what the intended behavior actually was that needed to be performed (e.g., Einstein \& McDaniel, 1996; Ellis, 1996). The uses of PM can either be habitual or one-off (or episodic) events. Intentions may need to be remembered over either the shorter-term (seconds, minutes or hours) or the longer-term (days, weeks or even months). Furthermore, the cues to prompt PM can be either event-based, where objects in the individual's surrounding environment serve as reminders that an intention needs to be acted upon (e.g., seeing a friend should remind the individual to pass on a message to him or her 
from another friend as intended), or time-based, where an intended action needs to be performed at some point in time in the future (e.g., needing to arrange travel insurance prior to leaving for a holiday the following week or to return a telephone call to a friend later the same day). Prospective memory can thus be divided broadly into two types depending upon the type of cue to support remembering to remember, namely eventbased PM (EBPM) and time-based PM (TBPM).

\section{Dyslexia and PM}

The following subsections review the evidence for PM deficits in dyslexia. Firstly, the focus of the current review on PM in adults is explained. After that, initial work in areas of cognition related to PM which informed the research program are considered. The review then addresses the evidence obtained from self-report studies, laboratory-based work, and tasks with more naturalistic demands.

\section{Focus of the review: $P M$ in adults}

Whilst much of the research literature on dyslexia has focused on children and adolescents, there is also a considerable body of evidence to document its continued impact into adulthood in a range of cognitive domains, including executive functions (e.g., Brosnan et al., 2002; Smith-Spark et al., 2016), working memory (e.g., NergårdNilssen \& Hulme, 2014; Smith-Spark et al., 2003; Smith-Spark \& Fisk, 2007), and rapid naming (Nergård-Nilssen \& Hulme, 2014). Broader cognitive difficulties have also been perceived by adults with dyslexia as occurring more frequently in their everyday lives (Leather, Hogh, Seiss \& Everatt, 2011; Smith-Spark, Fawcett, Nicolson \& Fisk, 2004; Smith-Spark, Henry et al., 2016). Unlike most areas of research on the effects of dyslexia, the majority of work on PM has been carried out on adults with dyslexia. This subsection will explain the reasons for this focus and give key 
information on the background characteristics of the samples used in the studies of PM in adults which are reviewed subsequently.

McLoughlin, Fitzgibbon, and Young (1994) have highlighted the differing demands on the cognition of an adult with dyslexia compared with that of a child. As a consequence, they argued that adults with dyslexia should not be treated simply as children with dyslexia who have "grown up" (p. 1). Instead, the authors identified the need for more research on the cognition of adults with dyslexia in its own right. With particular respect to $\mathrm{PM}$, the demands and responsibilities placed on an adult to remember to remember are likely to be far greater. In childhood, parents, teachers, and caregivers will often provide “external” PM support (c.f., Clark \& Chalmers’, 1998), reminding children of delayed intentions and ensuring that tasks are completed successfully at the appropriate point. Even when dyslexia is officially recognized in an adult and appropriate support provisions are in place, PM failure is still likely to be looked upon in an unfavorable light, especially when there are negative consequences attached to failing to meet deadlines or attend meetings (Smith-Spark, 2017).

These arguments provided the rationale for a recent program of research into PM in adults with dyslexia. Full details of the background characteristics of the samples tested are reported in Smith-Spark, Zięcik, and Sterling (2016a, 2016b, 2017a, 2017b). In all four studies, the participant groups were matched for general intelligence and differed on measures of reading and spelling. Educational psychologists’ reports were checked for all participants presenting with dyslexia. Comorbidity with attention deficit (hyperactivity) disorder (ADHD) was not identified in the educational psychologists' reports. Moreover, an overlapping sample of adults with dyslexia tested by SmithSpark, Henry et al. (2016) showed no evidence of attentional problems on the Test of Everyday Attention (Ward \& Ridgeway, 1994). 


\section{Early, indirect evidence suggestive of PM problems}

Whilst the effects of dyslexia on PM have only been explored directly very recently (Khan, 2014; Smith-Spark, Zięcik et al., 2016a, 2016b, 2017a, 2017b), earlier research has identified dyslexia-related difficulties in areas of cognition which could be argued to draw on similar cognitive abilities to those involved in PM. Problems in the areas of organization, time-keeping, and planning have been reported in dyslexia and the relevance of these abilities to PM has recently been highlighted by Waldum and McDaniel (2016) in relation to performing complex everyday PM tasks. In children with dyslexia, difficulties with organization (Torgeson, 1977) and planning (Condor, Anderson \& Saling, 1998; Klicpera, 1983; Levin, 1990) have been found under laboratory conditions. In adult university students with dyslexia, organization and timekeeping have been self-reported as being worse (Mortimore \& Crozier, 2006). Similar problems in adults with dyslexia have also been identified by their family and close friends (Smith-Spark et al., 2004).

\section{Subjective evidence provided by self and others}

Stanovich (2009) has argued that it is important to understand cognition at different levels, making a distinction between performance when carrying out a task optimally under laboratory conditions and when acting under typical, everyday conditions. He named these levels of cognition algorithmic and reflective respectively. Investigating the reflective level of cognition requires the researcher to tap into the day-to-day experiences and perceptions of individuals relating to their own typical levels of performance and, sometimes, these self-perceptions are corroborated by reports from close associates of these individuals. Two commonly used approaches to collecting selfreport data are by means of diary studies and questionnaires. Both approaches have provided insights into everyday PM in dyslexia. 
A diary study conducted by Smith-Spark (2000) required adults with and without dyslexia to record errors in their everyday cognition over a two-week period, writing down the nature of each slip that they committed and the circumstances prevailing at the time that it was made. Whilst the focus of the research was on slips of action (e.g., Reason, 1979; where habitual or routine actions go awry), the respondents also reported broader cognitive failures. Chief amongst these, a greater frequency of memory-related slips were reported by adults with dyslexia compared with adults without dyslexia. Many of these memory errors were retrospective (e.g., relating to forgetting previous actions or telling the same story to someone on more than one occasion) but there were also many memory failures involving PM (e.g., forgetting to post letters or to return library books as intended).

Self-report questionnaires can also be helpful in identifying patterns of PM performance over the longer-term (such as in the past month or six months). The Prospective and Retrospective Memory Questionnaire (PRMQ; Smith, Della Sala, Logie \& Maylor, 2000) is a 16-item self-report questionnaire measuring the relative frequency with which memory errors are perceived to be experienced by the respondent. The PRMQ probes both PM and retrospective memory (with the latter being episodic memory or memory for personally experienced past events). The questions on the PRMQ can be subdivided into different scales relating to the type of memory assessed (PM or retrospective memory), whether the memory was short- or longer-term, and whether the recall cue was environmental or internal to the self. The PRMQ has been used in two different studies to uncover higher frequencies of memory error in dyslexia (Khan, 2014; Smith-Spark, Zięcik et al., 2016a).

Khan (2014) administered the PRMQ (Smith et al., 2000) to children with and without dyslexia. The children with dyslexia self-reported more memory problems. In 
particular, self-cued memory was more prone to the effects of dyslexia than environmentally-cued memory. However, whilst this study identified increased PM problems in children with dyslexia, it should be noted that the PRMQ is aimed at adult respondents rather than children (indeed, Talbot \& Kerns, 2014, have produced an adapted version of the questionnaire specifically designed for children, in which parental ratings are taken). Furthermore, there was a wide range of ages in the sample, meaning that some individuals had more opportunity to exercise their PM, having a greater degree of independence as a result of their greater maturity. The comparative ages of the children with and without dyslexia were not reported, making it difficult to determine their relative opportunity for independent PM. Moreover, details of the two group's relative scores on the screening measures were not reported and the criteria for inclusion in the group with dyslexia were not fully defined.

Smith-Spark, Zięcik et al. (2016a) administered the PRMQ (Smith et al., 2000) to a sample of adults with and without dyslexia. Higher frequencies of both PM and retrospective memory difficulties were reported by the respondents with dyslexia, with these problems affecting memory over both the shorter- and longer-term and when memories were environmentally- or internally-cued.

The proxy-rating PRMQ (Crawford, Henry, Ward \& Blake, 2006) employs exactly the same questions as the PRMQ but is completed by a family member or close friend of the PRMQ respondent. Smith-Spark et al. (2016a) administered it to close associates of their PRMQ respondents. These proxy-ratings also indicated a heightened frequency of PM (and, again, retrospective memory) difficulty in adults with dyslexia. The proxy-rating results are important in validating the self-reports of the adults with dyslexia and ruling out the negative self-image and self-esteem associated with the 
condition in adulthood (e.g., Riddick, Sterling, Farmer \& Morgan, 1999) as an explanation of the reported increased frequency of memory failure.

Unlike the PRMQ (Smith et al., 2000), the Prospective Memory Questionnaire (PMQ; Hannon, Adams, Harrington, Fries-Dias \& Gibson, 1995) is a self-report questionnaire devoted entirely to the assessment of PM performance. The PMQ's 52 questions are divided between four subscales tapping different aspects of PM performance. Three of the subscales asked respondents to estimate how frequently in the past week, month or year they had experienced particular types of PM failure. The Long-term Episodic subscale assessed self-rated PM performance where there were extended durations between forming a PM intention and being able to act upon it. The Short-term Habitual subscale, on the other hand, probed the performance of PM tasks carried out regularly over short intervals. The Internally-cued subscale measured the frequency of PM failure when there were no external cues to facilitate remembering and performance was, thus, self-initiated. A further subscale, Techniques Used to Assist Recall, assessed the frequency with which respondents used a range of strategies and tools to support their PM.

Given the PMQ’s dedicated focus on PM, Smith-Spark, Zięcik et al. (2017a) administered it to adults with and without dyslexia in order to explore PM at a finergrained level than that permitted by Smith et al.’s (2000) PRMQ. On the Techniques Used to Assist Recall subscale, the adults with dyslexia self-reported more frequent use of tools and technology to aid their PM than the adults without dyslexia. The group difference on this subscale was then entered as a covariate when analyzing the responses to the scales designed to measure the frequency of PM failure (see Heffernan et al., 2006, for a similar approach with teenage excessive drinkers). Overall, the group with dyslexia reported more frequent problems with their PM. More specifically, they 
identified problems with long-term episodic and self-initiated PM. However, the groups did not differ in the frequency of PM failure when tasks were habitual and short-term.

\section{Laboratory-based evidence}

The first direct empirical observation of PM deficits in dyslexia was reported by SmithSpark, Zięcik, and Sterling (2016b). Three computerized TBPM tasks were administered to adults with and without dyslexia. These tasks varied in the load that ongoing behavior placed on working memory resources. The adults with dyslexia were found to have less accurate PM responses than the adults without dyslexia. They also made fewer clock checks during testing, although the overall pattern of the checks over the three-minute lead-up to a PM response being due was similar to that of the adults without dyslexia. A reduced frequency of clock checking suggests either a misplaced metacognitive confidence in their timing abilities or a greater degree of attentional resources being channelled towards the ongoing task to the detriment of clock checking. However, the latter explanation does not sit well with the accuracy of PM performance, where there was no interaction between participant group and the presence or absence of additional concurrent working memory load.

The Memory for Intentions Test (MIST; Raskin, Buckheit \& Sherrod, 2010) is a well-established clinical measure of PM. It was used by Smith-Spark, Zięcik et al. (2017a) to explore PM in adults with dyslexia over a range of different types of task, cue, and response. Over the course of the MIST’s 30-minute administration, eight PM tasks were set for the participant who was engaged in an ongoing activity (completing a word search puzzle) from which they had to break out to perform the PM tasks. The PM tasks varied in the type of cue to prompt a response (time or event), the delay between receiving a PM task instruction and the task needing to be performed (two minutes or 15 
minutes), and the type of response required (verbal or action). The adults with dyslexia displayed poorer PM overall on the MIST. At a finer-grained level, there was an interaction between dyslexia status and cue type. Compared with adults without dyslexia, the participants with dyslexia showed reduced levels of performance when TBPM was required but performed at an equivalent level when EBPM was needed. The two groups did not differ in their ability to recognize the PM instructions correctly when given a retrospective recognition test on completion of the MIST, suggesting that the PM instructions were successfully encoded and retained over the course of the test administration.

The nature of the MIST cue type interaction, in which no differences were found when event-based cues were presented, is consistent with the null findings obtained from two computerized EBPM tasks which compared adults with and without dyslexia (Zięcik, 2015). No group differences were found either when the processing of PM cues was consistent with task demands (such that both involved semantic processing; a high cue focality task) or when the ongoing task required semantic processing but event cues required featural processing (a low cue focality task). Whilst it is inadvisable to draw any conclusions from null results, the pattern of these findings is in general agreement with those arising from the MIST and suggest that TBPM, in particular, is prone to error in dyslexia.

\section{Naturalistic evidence}

The performance of adults with dyslexia has also been explored under more everyday task demands and conditions. Whilst findings from controlled laboratory experiments are very much the gold standard in terms of ensuring the validity of findings, it is important also to gain an understanding of how any problems so identified might actually play out in the day-to-day lives of individuals with dyslexia (cf., Stanovich, 
2009). Such work can then be used to demonstrate that dyslexia-related deficits in PM are not limited to often rather contrived tasks carried out in artificial settings but actually have a negative impact on the everyday PM of those with the condition. They, thus, provide an additional source of evidence to feed into supporting adults with dyslexia appropriately in education and the workplace, highlighting areas where reasonable adjustments to practices and procedures should be made.

Smith-Spark, Zięcik et al. (2016b) embedded a semi-naturalistic task within their computerized TBPM testing session. The participants were instructed to remind the experimenter to save a file 40 minutes later as, if they did not, the data would be lost. In the meantime, they were engaged in performing other PM tasks and received no further explicit reminders about this particular task. Compared with the adults without dyslexia, those with dyslexia were found to be much less likely to remind the experimenter to save the file, thus exhibiting a TBPM deficit in response to a more ecologically valid task.

The optional naturalistic task from Raskin et al.’s (2010) MIST was also employed by Smith-Spark, Zięcik et al. (2017a). The participants were asked to leave a telephone message for the experimenter exactly 24 hours after they had attended a laboratory-based session. This measure allowed an exploration of TBPM performance when a longer delay was imposed between intention formation. Furthermore, it placed the opportunity to act upon that intention outside the laboratory (since the laboratory setting itself provides some physical contextual cues to remember to perform a PM task). Responses were thus required under naturalistic conditions in the ongoing day-today life of the participant. The adults with dyslexia were found to be less likely to perform the task successfully and more likely to fail to complete it, whilst the adults in 
the group without dyslexia were more likely to complete the task successfully and less likely to fail to perform it.

As stated previously, under laboratory conditions, dyslexia-related deficits have been found to center on TBPM with EBPM performance being unaffected (SmithSpark, Zięcik et al., 2017a; Zięcik, 2015). There is, however, some evidence of EBPM difficulties over extended delay intervals and in everyday conditions. Smith-Spark, Zięcik et al. (2017b) found evidence of less accurate EBPM in adults with dyslexia when the delay between intention formation and intention execution was of a much longer duration, with the cue being presented one week after attending a laboratorybased testing session. The participants were requested to place a missed call to the experimenter when they received a text message. The PM task required the participant to ring the experimenter on the number from which the text message had been sent but to ring off before the telephone call was received. A mobile telephone was dedicated exclusively to the experiment and, in fact, the experimenter never answered calls to its number; instead, it was used simply to log participants' responses. Whilst making a missed call to a friend's number in order to exchange numbers is quite a common strategy in the United Kingdom, the task demands could be argued to be episodic, and to present some degree of novelty, in that leaving a missed call in response to a text message received whilst not in the company of the sender is not a usual or typical activity. The adults with dyslexia were less likely to respond successfully to the PM task and more likely to fail to respond. The reverse pattern of performance was found in the adults without dyslexia. Despite showing no difference in the initial encoding of the verbal instructions relating to the PM task and also reporting equivalent levels of motivation to perform the task successfully, the group with dyslexia were more likely to report having forgotten the task instructions over the course of the week between 
forming the intention and having the opportunity to act upon it. However, the two groups did not differ in the number of times they reported thinking about the task over the week's interval. Overall, these findings suggest that dyslexia-related deficits can be found in EBPM over extended delay intervals and when task conditions are episodic.

\section{How can dyslexia-related PM deficits be explained?}

There is, thus, a small body of literature investigating the effects of dyslexia on PM directly (Khan, 2014; Smith-Spark, 2000; Smith-Spark, Zięcik et al., 2016a, 2016b, 2017a, 2017b), whilst a number of other papers have provided indirect evidence that problems might exist in this area of cognition (Condor et al., 1998; Klicpera, 1983; Levin, 1990; Mortimore \& Crozier, 2006; Smith-Spark et al., 2004; Torgeson, 1977). Whilst the latter studies are useful in identifying where dyslexia-related problems might lie, this section will focus on the studies which have addressed PM explicitly. The results of the direct studies suggest that PM is most likely to be affected by dyslexia when TBPM rather than EBPM is needed (although see Smith-Spark, Zięcik et al., 2017b), when task demands are episodic rather than repeated or habitual, when delays are longer between intention formation and intention execution, and when performance has to be self-initiated rather than being offloaded to external objects.

Estimates of the likely prevalence rate of PM problems in dyslexia calculated from Smith-Spark, Zięcik et al. (2017a) suggest that around half of adults with dyslexia are likely to experience difficulties in this area of cognition. On the MIST, $40 \%$ of the adults with dyslexia had an overall PM accuracy score at least one SD lower than the control mean. On the PMQ, 50\% of adults with dyslexia had total PM scores more than one SD greater than the control mean, indicating more frequent difficulties with PM. Similarly, 61\% of the respondents with dyslexia on Smith et al.'s (2000) PRMQ 
produced total PM scores which were more than 1 SD higher than the mean of the control group, again identifying more frequent problems.

These estimated prevalence rates (albeit gained from a small number of studies) indicate the importance of understanding the effects of dyslexia on PM. It is necessary, therefore, to consider how such deficits can be explained by the dyslexia literature. Two broad theoretical approaches to dyslexia can be identified, those that consider dyslexia in terms of a core phonological processing deficit (Vellutino et al., 2004; Vellutino, 1979; for a review, see Castles \& Friedmann, 2013) and those that consider broader cognitive difficulties within their frameworks (e.g., Nicolson \& Fawcett, 1990; Nicolson, Fawcett \& Dean, 1995). By linking different theoretical approaches and findings from the research literature to specific PM components or task demands, it is possible to make some conjectures about the pattern of PM deficits in dyslexia. As stated previously, all PM tasks share two components (Einstein \& McDaniel, 1996; Ellis, 1996), a prospective component and a retrospective component. Possible explanations of dyslexia-related PM problems will now be considered in terms of these two components and, where appropriate, will be linked to dyslexia theory.

\section{Difficulties with the retrospective component of PM}

Prospective memory deficits in dyslexia might be explained by problems with the retrospective component of PM and, more specifically, in the encoding and retrieval of verbal information in memory.

Gonneaud et al. (2011) found that in a sample of typically ageing older adults, episodic retrospective memory abilities and the binding of associations between cue and action were found to be the strongest predictors of EBPM. There is some evidence to indicate that weaker binding of associations exists in dyslexia (Albano, Basso Garcia \& 
Cornoldi, 2016; Jones, Branigan, Parra \& Logie, 2013; Jones, Kuipers \& Thierry, 2016). For example, university students with dyslexia have been reported to have problems in binding associations between pairs of phonological and visual features (Jones et al., 2013). Cross-modal association problems may play out in PM task performance, since forming an association between task and cue is a one-off event and a (usually) verbal instruction needs to prompt a non-verbal action after a delay. The role of binding as a predictor of PM performance in dyslexia needs to be explored in future research.

Dyslexia-related problems with PM may thus arise from effective access to information in retrospective (or episodic) memory. In support of this argument, there is a small literature identifying long-term memory problems in children with dyslexia (McNamara \& Wong, 2003; Menghini, Carlesimo, Marotta, Finzi \& Vicari, 2010; Nelson \& Warrington, 1980). Similarly, dyslexia-related differences have been found in adults in long-term memory representations (Smith-Spark \& Moore, 2009), together with self-reported problems in remembering both facts (Mortimore \& Crozier, 2006) and episodically-experienced events (Smith-Spark, Zięcik et al., 2016a). However, as far as the author is aware, no studies have investigated whether phonological processing abilities (measured by basic tasks such as spoonerisms or phoneme deletion; e.g., Fawcett \& Nicolson, 1998) predict successful access to information held in verbal longterm memory in dyslexia, either in general or, more specifically, when PM is required. This should be investigated in future research.

With regard to the ability to remember PM instructions (i.e., the retrospective component of PM), different patterns of performance were found depending upon the delay interval and the method used to test the participants’ memory. Poorer recall was reported by the participants with dyslexia in the naturalistic EBPM study reported by 
Smith-Spark, Zięcik et al. (2017b). However, no group difference was found when recognition of instructions was required by the Retrospective Recognition Questionnaire on the MIST (Raskin et al., 2010) under laboratory conditions (Smith-Spark, Zięcik et al., 2017a). As well as highlighting the difference between recall and recognition of verbal material, testing for memory of the EBPM instructions took place after a week's interval compared with an interval of only 30 minutes in the case of the MIST. There was, thus, a much longer interval over which the instructions needed to be retained in memory, increasing the chances of decay. The results might, thus, suggest quicker decay of the PM task information from memory in the adults with dyslexia. However, it should be noted that no group differences were found in the self-reported frequency with which the participants thought about the task in the week between forming the intention and receiving the text message to cue enactment of the intention. In addition, since receiving text messages is generally a daily occurrence (at the very least), there is an argument in favour of reduced cue salience being present on the naturalistic task compared with a much higher cue salience when MIST event cues are presented in a laboratory setting by an unfamiliar experimenter sitting in front of the participant. From this perspective, a greater degree of self-initiated PM would be required by the naturalistic task. Self-initiated PM will be considered in more depth when the prospective component is considered in a later section.

Ramus and Szenkovits (2008) have argued that individuals with dyslexia may have greater difficulty accessing phonological representations under specific task demands (such as when short-term memory is required, when time constraints are in place, or when conscious awareness is needed). Less effective access to verbal information relating to PM task instructions might, therefore, result in lowered PM performance in individuals with dyslexia. 
Reduced effective access to phonological representations could explain, on two fronts, why poorer memory for PM instructions was found when recall was required (Smith-Spark, Zięcik et al., 2017b) than when recognition was tested (Smith-Spark, Zięcik et al., 2017a). Firstly, and most directly, the use of the MIST’s Retrospective Recognition Questionnaire (Raskin et al., 2010) could support access to weaker memory representations for the participants with dyslexia by cuing recall and, thereby, reducing or eliminating the difference between the groups in the accessibility of task instructions in memory. Secondly, participants were asked whether they recalled the PM instructions one week after having been given them. This extended delay interval meant that there was a greater opportunity for memory of the instructions to decay over the intervening period than when participants were tested on the MIST instructions immediately after the end of the test administration.

There is, thus, some evidence to suggest that problems with remembering PM task instructions and accessing them reliably at the time that they are needed may explain dyslexia-related problems with PM. In summary, based on the findings of Smith-Spark, Zięcik et al. (2016b, 2017a), the initial encoding of PM instructions seems not to present difficulties to adults with dyslexia (based on verbal checks by the experimenter that instructions had been understood and on the results of the MIST's Retrospective Recognition Questionnaire; Raskin et al., 2010). In terms of the maintenance of instructions over the intervening period, a more equivocal pattern is demonstrated. Individuals with dyslexia reported that they thought about instructions a similar number of times as adults without dyslexia, yet were more likely to report not remembering them (Smith-Spark, Zięcik et al., 2017b). Poorer access to representations of the PM task in memory could be argued to be shown in the reduced levels of accuracy produced by the adults with dyslexia across different studies (Smith-Spark, 
Zięcik et al., 2016b, 2017a, 2017b). However, further research is needed to determine whether the problems experienced by adults with dyslexia in the retrospective component of PM occur at the point of encoding instructions, their representation and maintenance in memory, or effective access to them at the point at which they are required. Comparing recognition of task instructions with recall over equivalent delay periods would also be informative in understanding where differences arise.

More broadly, evidence of difficulties with the retrospective component of PM can be linked quite plausibly to explanations of dyslexia which place phonological processing problems at the core of the condition. However, the Phonological Deficit Hypothesis (e.g., Vellutino, 1979) does not seem to provide so ready an explanation of the discrepancies found between TBPM and EBPM performance nor between habitual and episodic PM responses. However, it could be argued that self-initiated performance is likely to be based on internal, language-based strategies, whilst visual cues will be drawn upon to a greater extent when PM is environmentally supported. To explain these findings, an appeal to broader explanations of dyslexia is needed, together with a shift in focus to considering the prospective (or planning) component of PM.

\section{Difficulties with the prospective component of PM}

Executive functions constitute a range of higher-order cognitive functions such as planning, organizing behavior, dual-task management, inhibition, set shifting, maintaining task-relevant information in memory over the period for which it is required, and controlled access to information in long-term memory (e.g., Fisk \& Sharp, 2004; Miyake et al., 2000; Pennington \& Ozonoff, 1996). With regard to PM, the executive functions have been argued to be engaged at the stages of forming an intention to act in the future and executing that intention at the appropriate time-point in the future, whilst they are not considered to be so involved in intention retention over 
the intervening period (Martin, Kliegel \& McDaniel, 2003). Executive functions are argued to be engaged in PM especially when self-initiated or TBPM is required (e.g., Martin et al., 2003; McDaniel \& Einstein, 2000; although see Gonneaud et al., 2011, for an argument that executive functions are more engaged in EBPM tasks). As noted previously, more problems with self-initiated PM have been reported in both children and adults with dyslexia (Khan, 2014; Smith-Spark, Zięcik et al., 2017a), whilst dyslexia-related TBPM difficulties have been observed in adults with dyslexia (SmithSpark, Zięcik et al., 2016b, 2017a). This section will consider how dyslexia-related problems with the prospective component of PM might be explained in terms of the executive function difficulties also documented in adults with dyslexia (e.g., Brosnan et al., 2002; Smith-Spark, Henry et al., 2016).

Several specific executive functions have been implicated in PM in other populations. Inhibition is the ability to prevent a pre-potent or habitual response in favor of more novel task-appropriate behavior (e.g., Miyake et al., 2000). Set shifting, also known as task switching, reflects the ability to shift between cognitive operations or representational sets (e.g., Miyake et al., 2000). Both inhibition and set shifting have been found to predict the PM performance of adults (Bisiacchi, Schiff, Ciccola \& Kliegel, 2009; Gonneaud et al., 2011; Schnitzspahn, Stahl, Zeintl, Kaller \& Kliegel, 2013; although see Altgassen, Vetter, Phillips, Akgün \& Kliegel, 2014, who found a predictive relationship only in children and not adults). However, whilst these studies are useful in indicating how executive function difficulties might have a negative impact on PM, dyslexia itself was not under investigation. Research to explore the relative roles of a range of different executive functions in contributing to PM function in dyslexia is thus still required. 
Working memory (or “updating” within Miyake et al.’s, 2000, tripartite framework of executive functions), involves the temporary storage and processing of information in memory (e.g., Cowan, 2008). Like the executive functions already mentioned, working memory has also been found to be a positive predictor of PM (e.g., Marsh \& Hicks, 1998), especially under taxing cognitive conditions (Basso, Ferrari \& Palladino, 2010). It was identified as the only executive function found to influence developmental changes in TBPM abilities by Kretschmer, Voigt, Friedrich, Pfeiffer and Kliegel (2014).

The well-documented persistence of dyslexia-related working memory impairments into adulthood (e.g., Smith-Spark et al., 2003; Smith-Spark \& Fisk, 2007) might thus suggest themselves as a potential explanation for the poorer PM found in dyslexia. However, set against this, Smith-Spark et al. (2016b) found no group by cognitive load interaction when they added a further ongoing task which loaded on working memory resources. Deficits in TBPM were shown by the group with dyslexia regardless of working memory load, seemingly ruling out an explanation of dyslexiarelated TBPM problems couched in terms of working memory difficulties. However, as Smith-Spark et al. identified, the working memory load generated by the secondary ongoing task may not have been sufficiently taxing to affect TBPM performance.

The executive function of phonemic fluency requires the flexible access of information in long-term memory (Fisk \& Sharp, 2004). Phonemic fluency tasks require individuals to generate as many words as possible beginning with a certain letter in a specified time (usually 60 seconds). Using a within-subjects design, Smith-Spark, Moss, and Dyer (2016) found that phonemic fluency predicted the extent to which PM performance declined in adult non-problem drinkers when under the influence of alcohol compared with their performance when a placebo was administered. Individuals 
with better phonemic fluency abilities showed a smaller decline in PM performance under alcohol than those with weaker phonemic fluency abilities.

Given that phonemic fluency is an area in which adults with dyslexia have been found to have difficulties (e.g., Brosnan et al., 2002; Smith-Spark, Henry, Messer \& Zięcik, 2017), it may well be that at least some of the PM difficulties experienced by people with dyslexia are related to this area of executive functioning and, more particularly, the efficient and flexible access of information in verbal long-term memory (Fisk \& Sharp, 2004). Although the argument is more than a little tenuous at present, verbal fluency may provide a link between the contributions of executive functioning deficits and the retrospective memory difficulties considered previously in this section (see also Smith-Spark, Moss et al., 2016). However, more research to explore the relationship between verbal fluency, access to information in episodic memory, and PM is required, both in the general population and with respect to dyslexia in particular.

Therefore, given the links between executive functions and PM performance (e.g., Bisiacchi et al., 2009; Gonneaud et al., 2011; Martin et al., 2003; McDaniel \& Einstein, 2000; Schnitzspahn et al., 2013), it is possible that the executive functioning deficits shown by adults with dyslexia (e.g., Brosnan et al., 2002; Smith-Spark, Henry et al., 2016) may underlie their poorer PM performance, at least where task conditions are likely to draw upon EFs for effective PM.

It has been argued that individuals draw on their executive functions in order to break out from their ongoing behavior to perform the intended PM action at the point at which it is appropriate to respond (e.g., Cockburn, 1995; Van den Berg, Aarts, Midden \& Verplanken, 2004). Cockburn (1995) has argued that the Supervisory Attentional System (SAS) within Norman and Shallice's (1986) model of the control of action is involved in cue-monitoring and that this monitoring process draws on executive 
resources. The SAS coordinates, integrates, and controls information, drawing on attentional resources to modulate behavior. It is called upon when task novelty is high or poorly learnt action sequences are required. Cockburn also proposed that the SAS is required to act in order to allow the individual to break out from unrelated ongoing activity and carry out the PM task, suggesting that inhibition of ongoing responses (i.e., those controlled by contention scheduling processes within Norman and Shallice's model) is required for PM to proceed effectively.

Dyslexia-related PM deficits might thus result from the problems with SAS function proposed by Smith-Spark and Fisk (2007; see also Varvara et al., 2014), with a greater call upon the SAS being made when tasks are higher in novelty or, more generally, when they are more episodic in nature. Smith-Spark and Fisk (2007) have argued that adults with dyslexia may struggle with task novelty relative to adults without dyslexia. Their argument was based on evidence from a visuospatial working memory task, where students with dyslexia performed more poorly over the first half of the task but improved to achieve an equivalent level of recall accuracy to a group of age- and IQ-matched controls for the second half. Smith-Spark and Fisk argued that this pattern of performance might indicate a problem with setting up cognitive schemata to deal effectively with novel task demands, thereby implicating SAS dysfunction.

An explanation for PM deficits in dyslexia couched in terms of SAS deficits fits well with the nature of the problems uncovered by objective performance measures and also subjective reports, both of which have highlighted problems with episodic and/or novel tasks and self-initiated performance (Smith-Spark, Zięcik et al., 2016b, 2017a, 2017b). The argument that dyslexia-related PM deficits are more likely to be found when task demands are more novel is further supported by the absence of a selfreported group difference in short-term habitual PM on Hannon et al.’s (1995) PMQ 
(Smith-Spark, Zięcik et al., 2017a). Some PM theorists have argued that an individual must monitor the environment consciously for EBPM cues (as proposed by monitoring theory; e.g., Smith, 2003), whilst others have argued either that retrieval of intentions is more automatic (see spontaneous retrieval theory, e.g., Einstein \& McDaniel, 1996) or that it is a mixture of conscious and automatic processes depending on task demands (see the multiprocess theory, McDaniel \& Einstein, 2000). In dyslexia, the evidence to date (Smith-Spark, Zięcik et al., 2016a, 2016b, 2017a, 2017b) would seem to indicate that it is generally when conscious processes (c.f., Ramus \& Szenkovits, 2008) are needed that problems with PM emerge.

\section{Differences in time perception as an explanation}

A different explanation of the TBPM deficits reported by Smith-Spark, Zięcik et al. (2016b, 2017a) may lie in the time perception deficits which have been reported in dyslexia (e.g., Bruno \& Maguire, 1993; Khan, Abdal-hay, Qazi, Calle \& Castillo, 2014; Klein, 2002; Nicolson, Fawcett \& Dean, 1995; Tallal, 1980; Wolff, 2002).

In the general PM literature, there has only been limited exploration of the role of time perception as a predictor of TBPM performance and the findings are rather equivocal. McFarland and Glisky (2009) found no relationship between time perception abilities and PM accuracy. Similarly, more accurate time perception abilities have been found to predict monitoring (or clock-checking) behavior but not PM accuracy directly (Labelle, Graf, Grondin \& Gagné-Roy, 2009; Mioni \& Stablum, 2013; Vanneste, Baudouin, Bouazzaoui, \& Taconnat, 2016). In contrast, Mackinlay, Kliegel, and Mäntylä (2009) and Mioni, Santon, Stablum and Cornoldi (2016) have reported a positive relationship between time perception and the accuracy of PM performance.

However, the time perception tasks used to predict TBPM performance have generally tended to be in the seconds range (e.g., McFarland \& Glisky, 2009; Mioni et 
al., 2016; Mioni \& Stablum, 2013; Talbot \& Kerns, 2014). Whilst the weight of the evidence to date suggests a predictive relationship between time perception and PM performance (either directly, in terms of accuracy, or indirectly, through time monitoring behaviour), the choice of durations over which time perception is measured does not sit comfortably with the extended range of durations typically associated with TBPM tasks (where, at the very least, delays are frequently in the order of minutes). General PM research, therefore, needs to be extended to explore durations in the range of minutes as predictors of TBPM; such durations fall in the cognitive range of time perception and temporal judgements in this range are linked to the attentional processes distributed between cognitive task performance and temporal perception (e.g., Block, George \& Reed, 1980; Glicksohn, 2001; Thomas \& Weaver, 1975; Zakay \& Block, 1996). Such extended durations would map on to the timings of PM tasks more directly and might show stronger predictive relationships to PM accuracy rather than time monitoring. A similar gap exists in the dyslexia literature, where time perception studies have focused on the millisecond to second range and the relationship between timing abilities and TBPM accuracy has not yet been explored. More research is thus required to explore the extent to which time perception abilities predict the TBPM performance of adults with dyslexia.

Finally, it should be noted that time perception and executive functioning abilities have been found to be related (e.g., Carelli, Forman \& Mäntylä, 2008; Mäntylä, Carelli \& Forman, 2007; Ogden, Wearden \& Montgomery, 2014), so explanations of PM deficits in dyslexia based on either construct should not be treated necessarily as entirely separate.

\section{Supporting the PM of people with dyslexia}

Prospective memory deficits have been found under controlled laboratory conditions 
and in tasks with more naturalistic demands and environmental contexts for recall (Smith-Spark, Zięcik et al., 2016b, 2017a, 2017b). The poorer PM performance observed in adults with dyslexia is also apparent in their self-perceived frequency of PM failure in everyday life (Smith-Spark, Zięcik et al., 2016a, 2017a). Indeed, Smith-Spark, Zięcik et al. (2017a) found PM difficulties at both the algorithmic and reflective levels of cognition (Stanovich, 2009) in the same sample of participants. Adults with dyslexia showed worse performance on the MIST (Raskin et al., 2010) and also self-reported more frequent problems in everyday life on the PMQ (Hannon et al., 1995). Prospective memory deficits observed under laboratory conditions would, therefore, also seem to play out in the day-to-day lives of adults with dyslexia. This body of evidence, coming both from the laboratory setting and everyday life c.f., Stanovich, 2009), should be used to support the case for reasonable adjustments to be made to the educational and employment conditions of individuals with dyslexia.

At the most general level, it is recommended that people with dyslexia try wherever possible to i) avoid prolonged delays between formulating a delayed intention and having the opportunity to act upon it, ii) take accurate recordings of PM task instructions for later playback, iii) strengthen associations between PM cues and actions, and iv) convert TBPM to EBPM tasks. The latter two recommendations could be addressed jointly through the use of intention implementations (e.g., Gollwitzer, 1999; Gollwitzer \& Sheeran, 2006) in which if-then plans specify the how, when, and where of an intention being acted upon (for a meta-analytic review of the effectiveness of intention implementation in improving PM, see Chen et al., 2015). However, in older adults, Burkard, Rochat, Juillerat Van der Linden, Gold, and Van der Linden (2014) have found that the success of implementation intentions in improving PM was restricted to individuals with higher working memory spans. The effectiveness of 
intention implementation in facilitating PM may thus be moderated by the working memory problems found in adults with dyslexia (e.g., Smith-Spark \& Fisk, 2007; Smith-Spark et al., 2003; Smith-Spark, Henry et al., 2016). As mentioned previously, further research is needed to explore the contribution of working memory deficits to PM in dyslexia under higher cognitive load.

Altgassen, Kretschmer, and Schnitzspahn (2016) have investigated how PM can be improved through the use of repeated-encoding techniques to strengthen memory traces or through episodic future thinking (in which individuals are encouraged to project themselves into their personally experienced future, envisaging themselves performing the PM action). The latter technique proved best for adolescents, whilst the former was more effective in young adults. Research to explore the relative effectiveness of these different techniques should be explored in dyslexia.

Reid, Strnadová, and Cumming (2013) have highlighted the range of mobile technological supports available to adults with dyslexia, including help with organising and remembering tasks (for a broader perspective on distributed PM and sociotechnical systems, see Grundgeiger, Sanderson \& Dismukes, 2014). However, it should be noted that it may not be sufficient simply to provide people with dyslexia with good access to technological support through educational or employee support arrangements. The responses of Smith-Spark, Zięcik et al.’s (2017) adults with dyslexia indicated that, despite more frequent self-reported use of tools and technology to facilitate PM, they still experienced more frequent problems with PM than adults without dyslexia. This finding would suggest that providing adults with dyslexia with technological support for their PM is unlikely to be successful in the absence of explicit training and guidance in their optimal use. This concern fits with a wider literature on dyslexia-related problems with metacognition and the self-initiated identification, and adoption, of effective 
strategies to bring to bear on cognitive tasks (Bacon, Parmentier \& Barr, 2013; Meltzer, 1991; Torgeson \& Goldman, 1977).

\section{Conclusions}

This review paper has indicated how a range of different methodological approaches have been used to uncover poorer PM in dyslexia. These data triangulate to highlight problems mainly with TBPM, episodic tasks, PM over longer delay intervals, and selfinitiated performance. Some of these difficulties would appear to relate to impairments in accessing task-relevant information in long-term memory at the time at which it is required. It remains an open question as to whether executive functioning and time perception may also contribute to the PM difficulties experienced by adults with dyslexia across a range of settings. Further research in these areas has been suggested. Documenting the nature of PM failure in dyslexia is an important step towards ensuring that a greater error-proneness in day-to-day life tasks is recognised and, as a consequence, people with dyslexia are appropriately supported in educational and employment settings so that they can achieve their full potential.

\section{Acknowledgements}

The author would like to thank Dr Adam Zięcik and Dr Christopher Sterling for useful discussions concerning the ideas expressed in this paper. He is grateful also to Prof John Fisk for initial talks about PM and dyslexia and to Prof Angela Fawcett for useful recent discussions and encouragement.

\section{References}

Albano, D., Basso Garcia, R., \& Cornoldi, C. (2016). Deficits in working memory visual-phonological binding in children with dyslexia. Psychology \& Neuroscience, 9, 411-419. doi: 10.1037/pne0000066 
Altgassen, M., Kretschmer, A., \& Schnitzspahn, K. M. (2016). Future thinking instructions improve prospective memory performance in adolescents. Child Neuropsychology, 28, 1-18. doi: 10.1080/09297049.2016.1158247

Altgassen, M., Vetter, N. C., Phillips, L. H., Akgün, C., \& Kliegel, M. (2014). Theory of mind and switching predict perspective memory performance in adolescents. Journal of Experimental Child Psychology, 127, 163-175. doi: 10.1016/j.jecp.2014.03.009

Bacon, A. M., Parmentier, F. B. R., \& Barr, P. (2013). Visuospatial memory in dyslexia: Evidence for strategic deficits. Memory, 21, 189-209. doi: $10.1080 / 09658211.2012 .718789$

Basso, D., Ferrari, M., \& Palladino, P. (2010). Prospective memory and working memory: Asymmetrical effects during frontal lobe TMS stimulation. Neuropsychologia, 48, 3282-3290. doi:10.1016/j.neuropsychologia.2010.07.011

Bisiacchi, P. S., Schiff, S., Ciccola, A., \& Kliegel, M. (2009). The role of dual-task and task-switch in prospective memory: Behavioural data and neural correlates. Neuropsychologia, 47, 1362-1373. doi:10.1016/j.neuropsychologia.2009.01.034

Block, R. A., George, E. J., \& Reed, M. A. (1980). A watched pot sometimes boils: A study of duration experience. Acta Psychologica, 46, 81-94.

Bogaerts, L., Szmalec, A., Hachmann, W. M., Page, M. P. A., Woumans, E., \& Duyck, W. (2015). Increased susceptibility to proactive interference in adults with dyslexia? Memory, 23, 268-277.

Booth, J. N., Boyle, J. M. E., \& Kelly, S. W. (2010). Do tasks make a difference? Accounting for heterogeneity of performance of children with reading difficulties on tasks of executive function: Findings from a meta-analysis. British Journal of Developmental Psychology, 28, 133-176. doi: 10.1348/026151009X485432

Brosnan, M., Demetre, J., Hamill, S., Robson, K., Shepherd, H., \& Cody, G. (2002). Executive functioning in adults and children with developmental dyslexia. Neuropsychologia, 40, 2144-2155. Retrieved from https://www.journals.elsevier.com/neuropsychologia

Bruno, J. E., \& Maguire, S. R. (1993). Perception and allocation of time by dyslexic children. Perceptual and Motor Skills, 77, 419-432.

Burkard, C., Rochat, L. Juillerat Van der Linden, A.-C., Gold, G., Van der Linden, M. (2014). Is working memory necessary for implementation intentions to enhance prospective memory in older adults with cognitive problems? Journal of Applied Research in Memory and Cognition, 3, 37-43. doi: 10.1016/j.jarmac.2014.01.004

Carelli, M. G., Forman, H., \& Mäntylä, T. (2008). Sense of time and executive functioning in children and adults. Child Neuropsychology, 14, 372-386, doi: 10.1080/09297040701441411

Castles, A., \& Friedmann, N. (2014). Developmental Dyslexia and the Phonological Deficit Hypothesis. Mind and Language, 29, 270-285. doi: 10.1111/mila.12050 
Chen, X.-J., Wang, Y., Liu, L.-L., Cui, J.-F., Gan, M.-Y., Shum, D. H. K., \& Chan, R. C. K. (2015). The effect of implementation intention on prospective memory: A systematic and meta-analytic review. Psychiatry Research, 226, 14-22. doi: 10.1016/j.psychres.2015.01.011

Clark, A., \& Chalmers, D. J. (1998). The extended mind. Analysis, 58, 10-23.

Cockburn, J. (1995). Task interruption in prospective memory: a frontal lobe function? Cortex, 31, 87-97.

Condor, A., Anderson, V., \& Saling, M. (1998). Do reading disabled children have planning problems? Developmental Neuropsychology, 11, 485-502.

Cowan, N. (2008). What are the differences between long-term, short-term, and working memory? Progress in Brain Research, 169, 323-338. doi: 10.1016/S00796123(07)00020-9

Crawford, J. R., Henry, J. D., Ward, L. A., \& Blake, J. (2006). The Prospective and Retrospective Memory Questionnaire (PRMQ): Latent structure, normative data and discrepancy analysis for proxy-ratings. British Journal of Clinical Psychology, 45, 83104. doi: 10.1348/014466505X28748

Einstein, G. O., \& McDaniel, M. A. (1996). Retrieval processes in prospective memory: Theoretical approaches and some new empirical findings. In M. Brandimonte, G. O. Einstein, \& M. A. McDaniel (Eds.), Prospective memory: Theory and application (pp. 115-141). Mahwah, NJ: Erlbaum.

Ellis, J. (1996). Prospective memory or realization of delayed intentions: A conceptual framework for research. In M. Brandimonte, G. O. Einstein, \& M. A. McDaniel (Eds.), Prospective memory: Theory and applications (pp. l-23). Mahwah, NJ: Lawrence Erlbaum Associates.

Fawcett, A. J., \& Nicolson, R. I. (1998). The Dyslexia Adult Screening Test (DAST). London: The Psychological Corporation.

Fisk, J. E., \& Sharp, C. A. (2004). Age-related impairment in executive functioning: updating, inhibition, shifting, and access. Journal of Clinical and Experimental Neuropsychology, 26, 874-890. doi: 10.1080/13803390490510680

Glicksohn, J. (2001). Temporal cognition and the phenomenology of time: A multiplicative function for apparent duration. Consciousness and Cognition, 10, 1-25. doi: 10.1006/ccog.2000.0468

Gollwitzer, P. M. (1999). Implementation intentions: Strong effects of simple plans. American Psychologist, 54, 493-503. Retrieved from http://dx.doi.org/10.1037/0003066X.54.7.493 
Gollwitzer, P. M., \& Sheeran, P. (2006). Implementation intentions and goal achievement: A meta-analysis of effects and processes. Advances in Experimental Social Psychology, 38, 69-119. doi: 10.1016/S0065-2601(06)38002-1

Gonneaud, J., Kalpouzos, G., Bon, L., Viader, F., Eustache, F., \& Desgranges, B. (2011). Distinct and shared cognitive functions mediate event- and time-based prospective memory impairment in normal ageing. Memory, 19, 360-377. doi: $10.1080 / 09658211.2011 .570765$

Grundgeiger, T., Sanderson, P. M., \& Dismukes, R. K. (2014). Prospective memory in complex sociotechnical systems. Zeitschrift für Psychologie, 222, 100-109. doi: $10.1027 / 2151-2604 / \mathrm{a} 000171$

Hannon, R., Adams, P., Harrington, S., Fries-Dias, C., \& Gibson, M. (1995). Effects of brain injury and age on prospective memory self-rating and performance. Rehabilitation Psychology, 40, 289-298.

Heffernan, T., O’Neill, T., Ling, J., Holroyd, S., Bartholomew, J., \& Betney, G. (2006). Does excessive alcohol use in teenagers affect their everyday prospective memory? Clinical Effectiveness in Nursing, 9S3, e302-e307.

Jones, M. W., Branigan, H. P., Parra, M. A., \& Logie, R. H. (2013). Cross modal binding in developmental dyslexia. Journal of Experimental Psychology: Learning, Memory and Cognition, 39, 1807-1822. doi: 10.1037/a0033334

Jones, M. W., Kuipers, J.-R., \& Thierry, G. (2016). ERPs reveal the time-course of aberrant visual-phonological binding in developmental dyslexia. Frontiers in Human Neuroscience, 10, 71. doi: 10.3389/fnhum.2016.00071

Khan, A. (2014). An investigation into prospective memory in children with developmental dyslexia. Frontiers in Psychology, 5, 1308. doi:

10.3389/fpsyg.2014.01308

Khan, A., Abdal-hay, A., Qazi, T., Calle, C. L., \& Castillo, R. C. (2014). Time estimation in developmental dyslexia: An experimental investigation. Open Journal of Medical Psychology, 3, 373-381. doi: 10.4236/ojmp.2014.35039

Klein, R. M. (2002). Observations on the temporal correlates of reading failure. Reading and Writing, 15, 207-232.

Klicpera, C. (1983). Poor planning as a characteristic of problem behavior in children with dyslexia. Acta Paedopsychiatrica, 49, 73-82.

Kretschmer, A., Voigt, B., Friedrich, S., Pfeiffer, K., \& Kliegel, M. (2014). Time-based prospective memory in young children - Exploring executive functions as a developmental mechanism. Child Neuropsychology, 20, 662-676. doi: 10.1080/09297049.2016.1172561 
Labelle, A. A., Graf, P., Grondin, S., \& Gagné-Roy, L. (2009). Time-related processes in time-based prospective memory and in time-interval production. European Journal of Cognitive Psychology, 21, 501-521.

Leather, C., Hogh, H., Seiss, E., \& Everatt, J. (2011). Cognitive functioning and work success in adults with dyslexia. Dyslexia, 17, 327-338. doi: 10.1002/dys.441

Levin, B. E. (1990). Organisational deficits in dyslexia: Possible frontal lobe dysfunction. Developmental Neuropsychology, 6, 95-110.

Mackinlay, R. J., Kliegel, M., \& Mäntylä, T. (2009). Predictors of time-based prospective memory in children. Journal of Experimental Child Psychology, 102, 251264. doi: 10.1016/j.jecp.2008.08.006

Mäntylä, T. (1994). Remembering to remember: Adult age differences in prospective memory. Journal of Gerontology, 49, 276-282.

Mäntylä, T., Carelli, M. G., \& Forman, H. (2007). Time monitoring and executive functioning in children and adults. Journal of Experimental Child Psychology, 96, 1-19. doi: 10.1016/j.jecp.2006.08.003

Martin, M., Kliegel, M., \& McDaniel, M. A. (2003). The involvement of executive functions in prospective memory performance of adults. International Journal of Psychology, 38, 195-206.

Marsh, R. L., \& Hicks, J. L. (1998). Event-based prospective memory and executive control of working memory. Journal of Experimental Psychology: Learning, Memory, and Cognition, 24, 336-349.

McDaniel, M. A., \& Einstein, G. O. (2000). Strategic and automatic processes in prospective memory retrieval: A multiprocess perspective. Applied Cognitive Psychology, 14, 127-144.

McDaniel, M. A., \& Einstein, G. O. (2007). Prospective memory: An overview and synthesis of an emerging field. London: Sage.

McFarland, C. P. \& Glisky, E. L. (2009). Frontal lobe involvement in a task of timebased prospective memory. Neuropsychologia, 47, 1660-1669. doi:

10.1016/j.neuropsychologia.2009.02.023

McLoughlin, D., Fitzgibbon, G., \& Young, V. (1994). Adult dyslexia: Assessment, counselling and training. London: Whurr.

McNamara, J. K., \& Wong, B. (2003). Memory for everyday information in students with learning disabilities. Journal of Learning Disabilities, 36, 394-406.

Meltzer, L. (1991). Problem-solving strategies and academic performance in learning disabled students: Do subtypes exist? In L. V. Feagans, E. J. Short, \& L. J. Meltzer (Eds.), Subtypes of learning disabilities: Theoretical perspectives and research (pp. 163-188). Hillsdale, NJ: Lawrence Erlbaum Associates. 
Menghini, D., Carlesimo, G. A., Marotta, L., Finzi, A., \& Vicari, S. (2010).

Developmental dyslexia and explicit long-term memory. Dyslexia, 16, 213-225. doi: 10.1002/dys.410

Menghini, D., Finzi, A., Carlesimo, G. A., \& Vicari, S. (2011). Working memory impairment in children with developmental dyslexia: Is it just a phonological deficity? Developmental Neuropsychology, 36, 199-213. doi: 10.1080/87565641.2010.549868

Mioni, G., \& Stablum, F. (2013). Monitoring behaviour in a time-based prospective memory task: The involvement of executive functions and time perception. Memory, 22, 536-552. doi: 10.1080/09658211.2013.801987

Mioni, G., Santon, S., Stablum, F., \& Cornoldi, C. (2016). Time-based prospective memory difficulties in children with ADHD and the role of time perception and working memory. Child Neuropsychology, 19, 1-21. doi:

10.1080/09297049.2016.1172561

Miyake, A., Friedman, N. P., Emerson, M. J., Witzki, A. H., Howerter, A., \& Wager T. D. (2000). The unity and diversity of executive functions, and their contributions to complex "frontal lobe" tasks: A latent variable analysis. Cognitive Psychology, 41, 49100.

Mortimore, T., \& Crozier, W. R. (2006). Dyslexia and difficulties with study skills in higher education. Studies in Higher Education, 31, 235-251. doi:

10.1080/03075070600572173

Nelson, H. E., \& Warrington, E. K. (1980). An investigation of memory functions in dyslexic children. British Journal of Psychology, 71, 487-503.

Nergård-Nilssen, T., \& Hulme, C. (2014). Developmental dyslexia in adults: behavioural manifestations and cognitive correlates. Dyslexia, 20, 191-207. doi: 10.1002/dys.1477

Nicolson, R. I., \& Fawcett, A. J. (1990). Automaticity: A new framework for dyslexia research. Cognition, 35, 159-182.

Nicolson, R. I., Fawcett, A. J., \& Dean, P. (1995). Time estimation deficits in developmental dyslexia: Evidence of cerebellar involvement. Proceedings of the Royal Society of London, Series B: Biological Sciences, Vol. 259(No. 1354), pp. 43-47.

Norman, D. A., \& Shallice, T. (1986). Attention to action: Willed and automatic control of behaviour. In R. J. Davidson, G. E. Schwartz, \& D. Shapiro (Eds.), Consciousness and self-regulation: Advances in research and theory. Vol.4. (pp. 1-18). New York: Plenum Press.

Ogden, R., Wearden, J., \& Montgomery, C. (2014). The differential contribution of executive functions to temporal generalisation, reproduction and verbal estimation. Acta Psychologica, 152, 84-94. doi: 10.1016/j.actpsy.2014.07.014 
Pennington, B. F., \& Ozonoff, S. (1996). Executive functions and developmental psychopathology. Journal of Child Psychology and Psychiatry, 37, 51-87.

Ramus, F., \& Szenkovits, G. (2008). What phonological deficit? Quarterly Journal of Experimental Psychology, 61, 129-141. doi: 10.1080/17470210701508822

Raskin, S., Buckheit, C., \& Sherrod, C. (2010). Memory for Intentions Test. Lutz, FL: PAR.

Reason, J. T. (1979). Actions not as planned: The price of automatization. In G. Underwood \& R. Stevens (Eds.), Aspects of consciousness, Volume 1: Psychological issues (pp. 67-89). London: Academic Press.

Reid, G., Strnadová, I., \& Cumming, T. (2013). Expanding horizons for students with dyslexia in the $21^{\text {st }}$ century: Universal design and mobile technology. Journal of Research in Special Educational Needs, 13, 175-181. doi: 10.1111/1471-3802.12013

Riddick, B., Sterling, C., Farmer, M., \& Morgan, S. (1999). Self-esteem and anxiety in the educational histories of adult dyslexic students. Dyslexia, 5, 227-248.

Schnitzspahn, K. M., Stahl, C., Zeintl, M., Kaller, C. P., \& Kliegel, M. (2013). The role of shifting, updating and inhibition in prospective memory performance in young and older adults. Developmental Psychology, 49, 1544-1553. doi: 10.1037/a0030579

Smith, G., Della Sala, S., Logie, R. H., \& Maylor, E. A. (2000). Prospective and retrospective memory in normal ageing and dementia: A questionnaire study. Memory, 8, 311-321.

Smith, R. E. (2003). The cost of remembering to remember in event-based prospective memory: Investigating the capacity demands of delayed intention performance. Journal of Experimental Psychology: Learning, Memory, and Cognition, 29, 347-361.

Smith-Spark, J. H. (2000). Memory in adult dyslexics: An exploration of the working memory system. Unpublished PhD thesis, University of Sheffield, UK.

Smith-Spark, J. H. (2017). Everyday memory in adults with dyslexia. In A. Fawcett (Ed.), DAS Handbook 2017 (pp. 267-280). Singapore: Dyslexia Association of Singapore.

Smith-Spark, J. H., Fawcett, A. J., Nicolson, R. I., \& Fisk, J. E. (2004). Dyslexic students have more everyday cognitive lapses. Memory, 12, 174-182.

Smith-Spark, J. H., \& Fisk, J. E. (2007). Working memory functioning in developmental dyslexia. Memory, 15, 34-56. doi: 10.1080/09658210601043384

Smith-Spark, J. H., Fisk, J. E., Fawcett, A. J., \& Nicolson, R. I. (2003). Central executive impairments in adult dyslexics: Evidence from phonological and visuospatial working memory performance. European Journal of Cognitive Psychology, 15, 567587. 
Smith-Spark, J. H., Henry, L. A., Messer, D. J., Edvardsdottir, E., \& Zięcik, A. P. (2016). Executive functions in adults with developmental dyslexia. Research in Developmental Disabilities, 53-54, 323-341. doi: 10.1016/j.ridd.2016.03.001

Smith-Spark, J. H., Henry, L. A., Messer, D. J., \& Zięcik, A. P. (2017). Verbal and nonverbal fluency in adults with developmental dyslexia: Phonological processing or executive control problems? Dyslexia. doi: 10.1002/dys.1558

Smith-Spark, J. H., \& Moore, V. (2009). The representation and processing of familiar faces in dyslexia: Differences in age of acquisition effects. Dyslexia, 15, 129-146. doi: 10.1002/dys.365

Smith-Spark, J. H., Moss, A. C., \& Dyer, K. (2016). Do baseline executive functions mediate prospective memory performance under a moderate dose of alcohol? Frontiers in Psychology, 7, Article 1325. doi: 10.3389/fpsyg.2016.01325

Smith-Spark, J. H., Zięcik, A. P., \& Sterling, C. (2016a). Self-reports of increased prospective and retrospective memory problems in adults with developmental dyslexia. Dyslexia, 22, 245-262. doi: 10.1002/dys.1528

Smith-Spark, J. H., Zięcik, A. P., \& Sterling, C. (2016b). Time-based prospective memory in adults with developmental dyslexia. Research in Developmental Disabilities, 49-50, 34-46. doi: 10.1016/j.ridd.2015.11.006

Smith-Spark, J. H., Zięcik, A. P., \& Sterling, C. (2017a). Adults with developmental dyslexia show selective impairments in time-based and self-initiated prospective memory: Self-report and clinical evidence. Research in Developmental Disabilities, 62, 247-258. doi: 10.1016/j.ridd.2016.12.011

Smith-Spark, J. H., Zięcik, A. P., \& Sterling, C. (2017b). The event-based prospective memory of adults with developmental dyslexia under naturalistic conditions. Asia Pacific Journal of Developmental Differences, 4, 17-33.

Stanovich, K. E. (2009). Distinguishing the reflective, algorithmic, and autonomous minds: Is it time for a tri-process theory? In J. St. B. T. Evans \& K. Frankish (Eds.), In two minds: Dual processes and beyond (pp. 55-88). New York: Oxford University Press.

Talbot, K. D., \& Kerns, K. A. (2014). Event- and time-triggered remembering: The impact of attention deficit hyperactivity disorder on prospective memory performance in children. Journal of Experimental Child Psychology, 127, 126-143. doi: 10.1016/j.jecp.2014.02.011

Tallal, P. (1980). Auditory temporal perception, phonics and reading disabilities in children. Brain and Language, 9, 182-198.

Thomas, E. A. C., \& Weaver, W. B. (1975). Cognitive processing and time perception. Perception \& Psychophysics, 17, 363-367. 
Torgeson, J. K. (1977). The role of nonspecific factors in the task performance of learning disabled children: A theoretical assessment. Journal of Learning Disabilities, 10, 27-34.

Torgeson, J. K., \& Goldman, T. (1977). Verbal rehearsal and short-term memory in reading-disabled children. Child Development, 48, 56-60.

Van den Berg, S.M., Aarts, H., Midden, C., \& Verplanken, B. (2004). The role of executive processes in prospective memory tasks. European Journal of Cognitive Psychology, 16, 511-533.

Vanneste, S., Baudouin, A., Bouazzaoui, B., \& Taconnat, L. (2016). Age-related differences in time-based prospective memory: The role of time estimation in the clock monitoring strategy. Memory, 24, 812-825. doi: 10.1080/09658211.2015.1054837

Varvara, P., Varuzza, C., Sorrentino, A. C. P., Vicari, S., \& Menghini, D. (2014). Executive functions in developmental dyslexia. Frontiers in Human Neuroscience, 8(120). doi: 10.3389/fnhum.2014.00120

Vellutino, F. R. (1979). Dyslexia: Theory and research. Cambridge, MA: MIT Press.

Vellutino, F. R., Fletcher, J. M., Snowling, M. J., \& Scanlon, D. M. (2004). Specific reading disability (dyslexia): What have we learned in the past four decades? Journal of Child Psychology and Psychiatry, 45, 2-40.

Waldum, E. R., \& McDaniel, M. A. (2016). Why are you late? Investigating the role of time management in time-based prospective memory. Journal of Experimental Psychology: General, 145, 1049-1061. doi: 10.1037/xge0000183

Ward, T., \& Ridgeway, V. (1994). Test of Everyday Attention. Harlow, Essex: Pearson Assessment.

Winograd, E. (1988). Some observations on prospective remembering. In M. M. Gruneberg, P. E. Morris, \& R. N. Sykes (Eds.), Practical aspects of memory: Current research and issues (Vol. 1, pp. 348-353). Chichester, UK: Wiley.

Wolff, P. H. (2002). Timing precision and rhythm in developmental dyslexia. Reading and Writing, 15, 179-206.

Zakay, D., \& Block, R. A. (1996) The role of attention in time estimation processes. In M.A. Pastor \& J. Artieda (Eds.), Time, internal clocks and movement (pp. 143-164). Amsterdam: Elsevier Science.

Zięcik, A. P. (2015). Prospective memory in adults with developmental dyslexia. Unpublished PhD thesis, London South Bank University, UK. 